\title{
PENGARUH E-SERVICE QUALITY TERHADAP E-SATISFACTION PADA PENGGUNA APLIKASI MOBILE
}

\author{
Tirza Tiffani Haria') dan M. Rachman Mulyandi²) \\ ${ }^{1)}$ Matana University, Tangerang \\ tirzatiffaniharia@gmail.com \\ 2) Matana University, Tangerang \\ rachman.mulyandi@matanauniversity.ac.id
}

\begin{abstract}
Abstrak
Indonesia merupakan salah satu negara pengguna internet dan smartphone terbanyak di dunia. Konsep ekonomi digital mulai muncul pada dekade terakhir abad ke-20. Ekonomi digital mencakup aktivitas yang luas, dan untuk menunjang kegiatan tersebut, digunakan aplikasi mobile, seperti aplikasi mobile e-commerce, dan internet banking. Penelitian ini menggunakan metode penelitian kualitatif, sumber data penelitian ini didapatkan dari studi pustaka. Teknik pengumpulan data yang digunakan adalah literatur review. Data dianalisis dengan merujuk pada teknik analisis data kualitatif, dengan cara reduksi data, sajian data, dan penarikan kesimpulan. Objek penelitian dari penelitian ini adalah pengguna aplikasi mobile. Variabel independen dalam penelitian ini adalah e-service quality $(X)$, dan variabel dependen dalam penelitian ini adalah e-satisfaction $(Y)$. Berdasarkan hasil penelitian yang didapatkan, ditemukan bahwa variabel e-service quality berpengaruh signifikan terhadap esatisfaction pada produk jasa, atau intangible product. Namun pada aplikasi yang menyediakan produk tangible atau produk fisik, harus diperhatikan variabel mediasinya, yaitu nilai pengalaman (experiental value).
\end{abstract}

Kata Kunci: Ekonomi Digital, E-Service Quality, E-Customer Satisfaction, Aplikasi Mobile

\begin{abstract}
Indonesia is one of the most internet and smartphone user-oriented countries in the world. The concept of digital economy began to emerge in the last decade of the 20th century. The digital economy includes extensive activities, and to support these activities, mobile applications are used, such as e-commerce mobile applications, and internet banking. This study uses qualitative research methods, the data sources of this study were obtained from literature. The data collection technique used is literature review. Data were analyzed by referring to qualitative data analysis techniques, by means of data reduction, data presentation, and conclusion drawing. The object of research in this study is mobile application users. The independent variable in this study is e-service quality $(X)$, and the dependent variable in this study is e-satisfaction $(Y)$. Based on the results of the research obtained, it was found that the e-service quality variable had a significant effect on e-satisfaction on service products, or intangible products. But in applications that provide tangible products or physical products, the mediating variable must be considered, such as experiential value.
\end{abstract}

Keywords: Digital Economy, E-Service Quality, E-Customer Satisfaction. Mobile Applications

\section{PENDAHULUAN}

Internet merupakan salah satu bukti perkembangan teknologi saat ini, dengan adanya internet pencarian infomasi dan aktivitas sehari-hari dapat dilakukan dengan mudah. Indonesia menempati peringkat kelima sebagai negara pengguna internet tertinggi di dunia dengan jumlah 132,700,000 pengguna, atau sekitar $50,4 \%$ dari semua penduduk di Indonesia, dilihat dari tahun 2000-2017 maka pengguna internet di Indonesia tumbuh sebesar 6,535.0\%. 
Tabel 1.1 Top 20 Countries With Highest Number of Internet Users

TOP 20 COUNTRIES WITH HIGHEST NUMBER OF

INTERNET USERS - JUNE 30, 2017

\begin{tabular}{llrrrr}
\hline No. & Country or Region & $\begin{array}{c}\text { Population, } \\
\text { 2017 est. }\end{array}$ & $\begin{array}{c}\text { Internet Users } \\
\text { 30 June 2017 }\end{array}$ & $\begin{array}{c}\text { Internet } \\
\text { Penetration }\end{array}$ & $\begin{array}{c}\text { Growth }\left(^{*}\right) \\
2000-2017\end{array}$ \\
\hline 1 & China & $1,388,232,693$ & $738,539,792$ & $53.2 \%$ & $3,182.4 \%$ \\
2 & India & $1,342,512,706$ & $462,124,989$ & $34.4 \%$ & $9,142.5 \%$ \\
3 & United States & $326,474,013$ & $286,942,362$ & $87.9 \%$ & $200.9 \%$ \\
4 & Brazil & $211,243,220$ & $139,111,185$ & $65.9 \%$ & $2,682.2 \%$ \\
5 & Indonesia & $263,510,146$ & $132,700,000$ & $50.4 \%$ & $6,535.0 \%$ \\
\hline
\end{tabular}

Sumber : http://www.internetworldstats.com/top20.htm

Konsep ekonomi digital mulai muncul pada dekade terakhir abad ke-20. Ekonomi digital merupakan perdagangan barang dan jasa elektronik yang dihasilkan oleh bisnis elektronik melalui perdagangan elektronik dengan proses produksi dan manajemen elektronik yang berinteraksi dengan mitra dan pelanggannya melalui internet dan teknologi web. Ekonomi digital mencakup aktivitas yang luas, seperti e-commerce, toko aplikasi, jasa periklanan online, dan untuk menunjang kegiatan tersebut, digunakan aplikasi mobile. Menurut Pressman dan Bruce (2014), aplikasi mobile adalah aplikasi yang dirancang khusus untuk platform mobile.

Kualitas layanan elektronik atau e-service quality dapat diukur dari kemudahan yang diberikan perusahaan kepada pelanggan melalui media internet atau website. Kualitas layanan elektronik berarti sejauh mana situs web memfasilitasi kegiatan berbelanja, pembelian dan pengiriman produk dan jasa, serta distribusi secara efektif dan efisien (Jonathan, 2013).

E-service quality yang baik berdampak positif pada kepuasan pelanggan. Kepuasan dengan media elektronik atau e-satisfaction akan ditentukan oleh kualitas yang dirasakan dari e-service atau dapat juga disebut $e$ service quality (Sabiote et al, 2012, p.159).

Berdasarkan fenomena diatas, maka penelitian ini akan membahas mengenai pengaruh e-service quality terhadap e-loyalty pada pengguna aplikasi mobile.

\section{TINJAUAN PUSTAKA}

Menurut Pressman dan Bruce (2014), aplikasi mobile adalah aplikasi yang dirancang khusus untuk platform mobile seperti iOS, android, atau windows mobile. Aplikasi mobile memiliki user interface dengan mekanisme interaksi unik yang disediakan oleh platform mobile, interoperabilitas dengan sumber daya berbasis web yang menyediakan akses ke beragam informasi yang relevan dengan aplikasi, dan kemampuan pemrosesan lokal untuk pengumpulan, analisis, dan format informasi dengan cara yang paling sesuai untuk platform mobile. Aplikasi mobile juga menyediakan kemampuan penyimpanan persistent dalam platform.

Berdasarkan teori diatas, dapat disimpulkan bahwa jenis aplikasi mobile diantaranya adalah aplikasi mobile ecommerce seperti GoJek, Shopee, dan Tokopedia, kemudian aplikasi seperti internet banking, dan lain-lain.

E-Servqual dikembangkan untuk mengevaluasi suatu pelayanan yang diberikan pada jaringan internet. E-Service Quality didefinisikan sebagai perluasan dari kemampuan situs untuk memfasilitasi kegiatan belanja, pembelian, dan distribusi secara efektif dan efisien (Jonathan, 2013). Menurut Li et al., dalam Iswanca et al (2016), dimensi-dimensi pembentuk E-Service Quality adalah sebagai berikut.

\section{Ease Of Use}

Ease Of Use menggambarkan seberapa mudah pelanggan dalam menggunakan situs e-commerce. Situs harus dirancang untuk mempermudah pelanggan dalam 
pencarian, navigasi dan penggunaan. Ease Of Use dinilai sangat penting dalam dimensi E-Service Quality.

2. Web Design

Website adalah akses utama dalam proses pembelian. Kekurangan dalam design website dapat menghasilkan kesan negatif terhadap pelanggan, dan mungkin dapat membatalkan pembelian. Website adalah titik awal untuk mendapatkan kepercayaan pelanggan.

Desain Website dapat mempengaruhi persepsi pelanggan terhadap citra perusahaan, dan menarik pelanggan untuk melakukan pembelian online secara mudah dengan navigasi yang baik dan informasi yang berguna pada website. Website harus memberikan informasi dan fungsi yang dibutuhkan pelanggan.

3. Reliability

Menurut beberapa penelitian Reliability adalah dimensi yang paling penting dari E-Service Quality, karena dapat membuat pelanggan percaya bahwa perusahaan akan melakukan apa yang telah dijanjikan adalah hal yang sangat penting. Reliability juga dapat membuat pelanggan melihat konsistensi dan kredibilitas dari perusahaan.

4. System Availability

System Availability mengacu pada fungsi teknis yang benar dari website. sehingga pelanggan selalu dapat mengakses layanan online yang diberikan perusahaan, hal ini dapat membuat perusahaan memiliki citra yang baik di mata pelanggan. Ketika pelanggan tidak dapat mengakses sistem online pada saat mereka membutuhkan pelayanan online, pelanggan akan beralih ke perusahaan lainnya.

5. Privacy

Privacy berarti sejauh mana situs tersebut aman dan informasi pelanggan terlindungi. Resiko di dunia maya berasal dari kemungkinan penyalahgunaan data keuangan dan data pribadi pelanggan.

6. Responsiveness

Responsiveness berarti penanganan masalah yang efektif dan memberikan respon via internet. Pelayanan cepat dari perusahaan via internet dapat membuat pelanggan merasa lebih nyaman saat melakukan pembelian.

\section{Empathy}

Memberikan perhatian secara individu kepada pelanggan dapat menunjukkan empati terhadap pelanggan. Perusahaan harus selalu menyadari kebutuhan pelanggan dan menunjukkan pemahaman terhadap apa yang dibutuhkan pelanggan. Empati sangat penting dalam persepsi pelanggan terhadap kualitas pelayanan elektronik tanpa adanya pertemuan langsung.

Kepuasan pelanggan adalah hasil dari keberhasilan penyampaian kualitas layanan dan kualitas produk yang sesuai dengan harapan pelanggan. E-satisfaction adalah keadaan psikologis yang dihasilkan ketika seorang pelanggan puas dan tidak lagi mencari alternatif lain selain website yang ia gunakan saat itu (Oliver, 2003).

E-customer satisfaction adalah evaluasi pasca-konsumsi mengenai seberapa baik penyedia produk dan jasa memenuhi atau melebihi harapan konsumen (Hansen dan Jonsson, 2013). Kepuasan atau ketidakpuasan pembeli ditentukan oleh evaluasi konsumen terhadap perbedaan antara ekspetasi awal dengan persepsi terhadap kinerja produk yang sebenarnya setelah pemakaian produk.

Ada empat metode yang dapat digunakan untuk mengukur tingkat kepuasan pelanggan yaitu (Tjiptono dan Chandra, 2011):

1. Sistem keluhan dan saran

Setiap organisasi yang berorientasi pada pelanggan (customer-oriented) perlu menyediakan kesempatan dan akses yang mudah dan nyaman bagi para pelanggannya untuk menyampaikan saran, kritik, pendapat, dan keluhan mereka. Media yang dapat digunakan seperti, saluran khusus bebas pulsa, website, dan sebagainya.

2. Ghost shopping (mystery shopping)

Perusahaan dapat mempekerjakan beberapa orang ghost shoppers untuk berpura-pura menjadi pelanggan potensial produk perusahaan dan pesaing, dengan cara berinteraksi 
dengan staf penyedia jasa dan menggunakan produk/jasa perusahaan.

3. Lost customer analysis

Perusahaan dapat menghubungi para pelanggan yang telah berhenti membeli atau yang telah berpindah pemasok agar dapat memahami mengapa hal tersebut terjadi dan supaya dapat mengambil kebijakan untuk perbaikan selanjutnya.

4. Survei kepuasan pelanggan

Survei dapat dilakukan melalui telepon, e-mail, website, atau wawancara langsung. Melalui survei, perusahaan akan memperoleh tanggapan dan balikan secara langsung dari pelanggan dan juga memberikan kesan positif bahwa perusahaan menaruh perhatian terhadap para pelanggannya.

Indikator-indikator variabel kepuasan konsumen yaitu (Prayitno, 2015):

1. Puas terhadap kualitas pelayanan.

2. Merekomendasikan produk/jasa kepada orang lain.

3. Memiliki keinginan untuk tidak berpindah ke produk/jasa yang lain.

4. Bangga menggunakan jasa/produk yang digunakan.

5. Puas terhadap hasil akhir produk/jasa yang diterima.

\section{METODE PENELITIAN}

Penelitian ini menggunakan metode penelitian kualitatif. Sumber data penelitian ini berasal dari sumber sekunder, yaitu studi pustaka. Teknik pengumpulan data yang digunakan dalam penulisan makalah ini adalah literature review. Data yang didapatkan akan dianalisis dengan merujuk pada teknik analisis data kualitatif, dengan cara reduksi data, sajian data, dan penarikan kesimpulan (Yuliansyah, Hakim, \& Suryani, 2015). Objek penelitian dari penelitian ini adalah pengguna aplikasi mobile. Variabel independen dalam penelitian ini adalah $e$ service quality $(\mathrm{X})$, dan variabel dependen dalam penelitian ini adalah e-satisfaction $(Y)$.

\section{HASIL DAN PEMBAHASAN}

Berdasarkan hasil literature review dari jurnal sebelumnya, yaitu jurnal dengan judul " $E$ Service Quality terhadap Kepuasan dan Loyalitas Pelanggan dalam Penggunaan Internet Banking" oleh $\mathrm{Ni}$ Made Savitri Anggraeni dan $\mathrm{Ni}$ Nyoman Kerti Yasa, ditemukan bahwa e-service quality berpengaruh positif dan signifikan terhadap kepuasan pelanggan. Semakin baik kualitas layanan yang diberikan, maka kepuasan pelanggan juga meningkat.

Demikian juga dengan jurnal yang berjudul "Pengaruh E-Service Quality Terhadap Perceived Value dan E-customer Satisfaction (Survei pada Pelanggan GoRide yang Menggunakan Mobile Application Go-Jek di Kota Malang)" oleh Yustisi Suci Widiaputri, Suharyono, dan Aniesa Samira Bafadhal, ditemukan bahwa variabel $E$ Service Quality terbukti berpengaruh signifikan terhadap variabel E-Customer Satisfaction, dimana kemudahan penggunaan layanan dalam e-service quality aan menciptakan e-customer satisfaction.

Namun, pada jurnal yang berjudul "Pengaruh E-Service Quality Ritel Online di Indonesia terhadap E-Satisfaction melalui Experiental Value sebagai Variabel Antara (Studi pada Zalora Indonesia)" oleh Edo Satria Dinata dan Achmad Fauzi, ditemukan bahwa tidak terdapat pengaruh yang signifikan antara kualitas pelayanan elektronik terhadap kepuasan konsumen online secara langsung, namun terdapat terdapat pengaruh yang signifikan antara kualitas pelayanan elektronik terhadap kepuasan konsumen online melalui mediasi nilai pengalaman (experiental value).

\section{KESIMPULAN}

Berdasarkan hasil penelitian yang didapatkan, ditemukan bahwa variabel $e$ service quality berpengaruh signifikan terhadap e-satisfaction pada produk jasa, atau intangible product. Namun pada aplikasi yang menyediakan produk tangible atau produk fisik, harus diperhatikan variabel mediasinya, yaitu nilai pengalaman (experiental value).

Saran untuk penelitian selanjutnya, jika ingin meneliti produk jasa, atau intangible product, dapat menggunakan variabel $\mathrm{X}$ dan Y saja. Namun jika ingin meneliti tangible 
product, maka sebaiknya digunakan variabel $\mathrm{X}, \mathrm{Y}$, dan Z.

\section{DAFTAR PUSTAKA}

Databoks. (2018, Februari 12). 2022, Penjualan E-Commerce Indonesia Mencapai US\$16 Miliar. Retrieved From Katadata.Co.Id:

https://databoks.katadata.co.id/datapublis h/2018/02/12/2022-penjualan-ecommerce-indonesia-mencapai-rp-16miliar

Ghalandari, K. (2012). The Effect of Performance Expectancy, Effort Expectancy, Social Influence and Facilitating Conditions on Acceptance of E-Banking Services in Iran: the Moderating Role of Age and Gender. Middle-East Journal of Scientific Research, 12848.

Hojeghan, S. B., \& Fangareh, A. N. (2011). Digital Economy and Tourism Impacts, Influences, and Challanges. Iran: Procedia Social and Behavioral Sciences. Imron, A. (2013). Proses Manajemen Tingkat Satuan Pendidikan. Jakarta: Bumi Aksara. Jonathan, H. (2013). Analisis Pengaruh EService Quality Terhadap Customer Satisfaction Yang Berdampak Pada Customer Loyalty PT Bayu Buana Travel TBK. The Winners, 104-112.

Kenneth, L. C., \& Laudon P, J. (2014). Management Information System Edisi 13. England: Pearson Educatin Limited.

Kotler, P. T., \& Keller, K. L. (2012). Marketing Management 14th Edition. Pearson.

Laudon, \& Traver. (2012). E-commerce 2012: Businees, Technology, Society. 8 ed. Kendallville: Pearson.

Mahatma, R. (2017). Buat Toko Online. Retrieved from Data Statistik Mengenai Pertumbuhan Pangsa Pasar E-Commerce di Indonesia Saat Ini:

https://buattokoonline.id/data-statistikmengenai-pertumbuhan-pangsa-pasar-ecommerce-di-indonesia-saat-ini/

Nextren. (2018, Januari 19). Inilah Tren ECommerce 2018 di Indonesia, Menurut Toko Online Ini. Retrieved from nextren.grid.id: http://nextren.grid.id/read/0124363/inilahtren-e-commerce-2018-di-indonesiamenurut-toko-online-ini?page $=$ all
Ryza, P. (2018, Maret 22). Mengenal Program Loyalitas di Indonesia. Retrieved from dailysocial.id: https://dailysocial.id/post/mengenalprogram-loyalitas-di-indonesia

Sabiote, C. M., Dolores, M., \& Castaneda, A. (2012). E-service quality as antecedent to e-satisfaction The moderating effect of culture. Online Information Review Vol. 36 No. 2, 161.

Tjiptono, F., \& Chandra, G. (2016). Service, Quality Dan Satisfaction Edisi 4.

Turban, E., King, D., Lee, J. K., Warkentin, M., \& Chung, H. M. (2002). Electronic Commerce 2002: A Managerial Perspective, 2nd Edition. Kendallville: Pearson. 
Haria \& Mulyandi / Pengarung E-Service Quality terhadap E-Satisfaction ... 